\title{
Persistence of Left Superior Vena Cava in Patient submitted a Pacemaker Implantation
}

\author{
Persistência de Veia Cava Superior Esquerda em Paciente Submetido a \\ Implante de Marca-Passo
}

Sara Carneiro Vicente Bueno ${ }^{1, *}$, Arnaldo Duarte Lourenço ${ }^{1}$

ORCID IDS

Bueno SCV (D) https://orcid.org/0000-0001-6638-2492

Lourenço AD (D) https://orcid.org/0000-0003-3582-6534

\section{ABSTRACT}

The persistence of the left superior vena cava (PLSVC) is the most frequent thoracic venous malformation, however rare, and with a usually accidental diagnosis. Recurringly, its greatest suspicion is realized in the intraoperative act related to a technical difficulty in performing the procedure, even by more experienced professionals. Case report: patient is 77 years old, woman, chagasic, submitted a definitive pacemaker implant, being the diagnosis of persistence left superior vena cava realized during the surgical procedure. The patient did not present intercurrence during the procedure and developed with substantial clinical improvement after the implantation of the electronic cardiac device, and remaining asymptomatic.

KEYWORDS: Superior vena cava; Vascular malformations; Artificial pacemaker.

\section{RESUMO}

A persistência da veia cava superior esquerda (PCVSE) é a malformação venosa torácica mais frequente, porém rara e com diagnóstico habitualmente acidental. Recorrentemente, sua maior suspeita é realizada no ato intraoperatório relacionado a uma dificuldade técnica na realização do procedimento, mesmo por profissionais mais experientes. Relato de caso: Paciente de 77 anos, sexo feminino, chagásica, submetida a implante de marcapasso definitivo, sendo o diagnóstico de persistência de veia cava superior esquerda realizado durante o procedimento cirúrgico. A paciente não apresentou intercorrência durante o procedimento e evoluiu com melhora clínica substancial após o implante do dispositivo cardíaco eletrônico, mantendo-se assintomática.

PALAVRAS-CHAVE: Veia cava superior; Malformações vasculares; Marcapasso artificial.

1. Hospital Ana Costa - Setor de Estimulação Cardíaca Artificial - Santos/SP - Brazil.

*Correspondence author: sara.cvicente@gmail.com

Received: 16 May 2018 | Accepted: 04 Feb 2019

Section Editor: J. Tarcísio Medeiros de Vasconcelos 


\section{INTRODUCTION}

Initially described in the 1950 s, persistence left superior vena cava (PLSVC) is the most common venous vascular anomaly found in the thorax, despite its rarity ${ }^{1}$ Its prevalence is between 0.3 and $0.5 \%$ of the world population, however, when associated with congenital heart diseases, it rises to 2.8 to $4.3 \%^{1-3}$. In the majority of cases, the right superior vena cava is present, being rare the finding of isolated PLSVC ${ }^{4}$.

During the embryological phase, the drainage is made by the cardinal veins: head, neck, and arms drain into the right atrium through the right and left anterior cardinal veins ${ }^{1}$. Around the eighth week of gestation, the left innominate vein joins the anterior portions of the cardinal veins. The right anterior cardinal vein becomes the right superior vena cava ${ }^{1-3}$. The left anterior cardinal vein is occluded, originating the Marshall's ligament ${ }^{1}$. When this vein does not degenerate, the left superior vena cava develops, which will drain into the right atrium through the coronary sinus ${ }^{1,3}$. PLSVC is an embryological condition that does not cause major complications or symptoms and is generally identified during implantation of cardiac devices, central venous catheters or thoracic surgical procedures ${ }^{1,4}$. It then becomes a possible obstacle, even for experienced professionals ${ }^{1,5}$.

Despite its benignity related to the symptomatology, this anomaly makes the patient more vulnerable to the development of cardiac arrhythmias, especially by changes in the atrioventricular node and in the bundle of $\mathrm{His}^{4,6}$. In a minority of cases, this condition may partially obstruct the mitral valve, generating a loss in the left atrioventricular flow, and then the possibility of the patient developing symptoms ${ }^{4}$.

Its presence may be associated with other cardiovascular abnormalities, such as atrial septal defect, bicuspid aortic valve, aortic coarctation and ostial atresia of the coronary sinus ${ }^{5}$.

\section{CASE REPORT}

A 77 years old, woman patient with a personal antecedent of Chagas' disease and heart failure, in optimized treatment, is hospitalized with syncope related to the recent initiate orthostatic position associated with dyspnea and lower limb edema. On the electrocardiogram, the patient presented sinus rhythm with evidence of right branch block. During hospitalization, transthoracic echocardiography (ECHO 2D) was realized, which showed a significant increase in the right atrial volume, with a significant contractile deficit of the left ventricle and mild right ventricle, at the expense of diffuse hypokinesia of both and dilation of the coronary sinus. During the examination, the patient remained in the validity of arrhythmia. It was chosen to perform a 24 hour of Holter, three channels, in which the mean heart rate was 50 beats per minute in sinus rhythm, right branch block and total atrioventricular block during the exam period. After evaluation, it was defined that the patient would be submitted to permanent pacemaker implantation. During the procedure, when the wires were passed through the right subclavian vein puncture, a diagnosis of PLSVC was made, along the path they presented, descending from the left, and there was difficulty in the passage of the ventricular electrode cable, denoting the large dilation of the coronary sinus presented to ECHO 2D. The procedure ended without intercurrence, with adequate positioning of the atrial and ventricular electrodes. The patient remained hospitalized for post-surgical clinical evaluation, evolving without complications. The patient was discharged from the hospital and kept in regular cardiology, and was asymptomatic, with a complete resumption of its usual routine.

\section{DISCUSSION}

The suspicion of PLSVC occurs, in general, at the intraoperative moment, however, its existence can also be suggested through examinations ${ }^{4}$. Thorax radiography shows an abnormal contour of the upper mediastinum to the left, with a prominence below the aortic arch and absence of the rectification line of the right superior vena cava ${ }^{1,3}$ (Fig. 1).

In $2 \mathrm{D}$ ECHO dilation of the coronary sinus can be found, in this case, measured in $2.2 \mathrm{~cm}$, corroborating the diagnosis ${ }^{6}$. In this examination, the presence of PLSVC was confirmed by the injection of saline solution agitated in the left upper limb, demonstrating the early occurrence of blisters in the coronary sinus, subsequently drained to the right atrium ${ }^{1,5}$ (Fig 2). Computed tomography and 


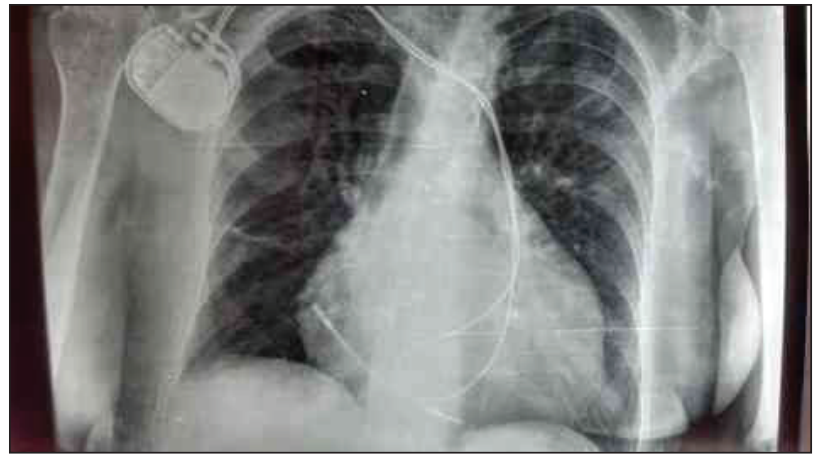

Figure 1. Thorax radiography demonstrating the positioning of the atrial and ventricular leads at the conclusion of the procedure.

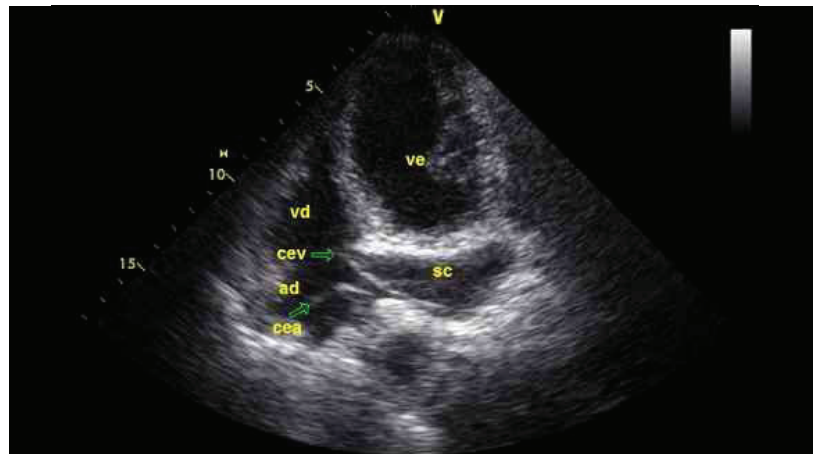

Figure 2. Two-dimensional echocardiogram demonstrating the relationship of the right atrium and coronary sinus enlargement $(2.2 \mathrm{~cm})$ with the passage and positioning of electrode cables in the right atrium and right ventricle.

magnetic resonance can confirm the diagnosis of PLSVC, assessing in greater detail the anatomy of the region ${ }^{1}$.

The patient with PLSVC presents a challenge in the positioning of devices: initially, because the diagnosis is not known, the implantation of the device is different from usual, and secondly, because these technical difficulties can lead to the displacement of the electrode and to the lesion of the vessel and the right ventricle (RV), which can generate risks to the patient ${ }^{6}$.

PLSVC is a rare condition that does not add clinical harm to the patient, in most cases. Its diagnosis is usually incidental, especially after the passage of central venous access, catheters or implantation of other cardiac devices, such as, for example, pacemaker. However, with the increased necessity for invasive thoracic procedures, their presence may generate greater complexity during the method, sometimes hindering the progression of the guide and occurring the chance of injury of the structures involved, as already mentioned. The precocious suspicion, through previous examinations (preoperative), is of great value, since it prepares the professional to perform the procedure, making it quicker and safer for the patient, and with less chance of complications.

The patient with PLSVC should be submitted to complementary investigation, to the exclusion of other congenital anomalies. Despite the possible technical difficulty that PLSVC may cause even the most experienced physician, its presence does not contraindicate the performance of any procedure that requires the use of the veins that reach the heart.

\section{AUTHORS' CONTRIBUTION}

Conceptualization, Lourenço A; Methodology, Lourenço A; Investigation, Lourenço A; Writing - First version, Lourenço A and Bueno S; Writing - Review \& Edition, Lourenço A and Bueno S; Supervision, Lourenço A.

\section{REFERENCES}

1. Bragança EOV. Persistência de veia cava superior esquerda e implante de dispositivos cardíacos eletrônicos. Rev LatinoAm Marcapasso Arritmia. 203;26(4):260-70.

2. Altunkas A, Altunkas F. A very rare subgroup of persistent left superior vena cava in an adult: isolated persistent left superior vena cava with absence of the congenital heart diseases. Acta Med Anatolia. 2014;2(1):32-3.

3. Rodríguez-Fernández JA, Almazán-Soo A. Pacemaker lead implant via the persistent left superior vena cava. Arch Cardiol Mex. 2005;75(Suppl 3):S3-106-12.

4. Bernardes MVAA, Kool R, Ludtke IN, Luz MA, Erzinger FL. Veia cava superior esquerda persistente: relato de caso. J Vasc Bras. 2016;15(2)153-7. https://doi. org/10.1590\%2F1677-5449.002815

5. Goyal SK, Punnam SR, Gita V, Ruberg FL. Persistent left superior vena cava: a case report and review of literature. Cardiovasc Ultrasound. 2008;6:50. https://doi. org/10.1186/1476-7120-6-50

6. Biffi M, Massaro G, Diemberger I, Martignani C, Corzani A, Ziacchi M. Cardiac resynchronization therapy in persistent left superior vena cava: can you do it two-leads-only? Heart Rhythm Case Rep. 2017;3(1):30-2. https://doi. org/10.1016\%2Fj.hrcr.2016.08.004 